\title{
MESIN PENIRIS TIGA JENIS KRIPIK BERBASIS MOTOR LISTRIK TIGA FASA DAN MIKROKONTROLER ARDUINO UNO
}

\author{
Graha Prasidya ${ }^{1}$, Rasional Sitepu $^{2 *}$, Widya Andyardja ${ }^{3}$ \\ ${ }^{1,2,3}$ Jurusan Teknik Elektro, Fakultas Teknik, Universitas Katolik Widya Mandala Surabaya \\ ${ }^{2}$ Program Studi Program Profesi Insinyur, Fakultas Teknik, Universitas Katolik Widya Mandala \\ Surabaya \\ *Corresponding author, e-mail: rasional@ukwms.ac.id
}

\begin{abstract}
Abstrak - Keripik merupakan makanan ringan khas indonesia yang banyak digemari oleh seluruh masyarakat. Dalam proses pembuatan keripik dibutuhkan tahap pengeringan minyak. Tujuan pengeringan minyak adalah untuk menghilangkan kandungan minyak yang ada pada kripik tersebut agar kripiknya tidak tengik. Metode konvensional yang biasa digunakan untuk mengeluarkan kandungan minyak tersebut adalah dengan meletakkan kripik yang dikeringkan pada kertas. Kertas berfungsi menyerap minyak yang pada keripik tersebut. Pada makalah ini akan disampaikan sebuah mesin pengering keripik berbasis motor listrik. Mesin ini dibangun atas motor induksi sebagai pengerak, inverter sebagai pengatur kecepatan, dan mikrokontroler arduino uno sebagai pengendali sensor. Metode pembuatan menggunakan desain eksperimen. Mesin ini akan berhenti secara otomatis apabila keripik sudah kering. Tiga jenis kripik sudah berhasil dikeringkan dengan mesin ini.
\end{abstract}

Kata kunci: peniris kripik, motor listrik, arduino uno, inverter

\begin{abstract}
Chips are a typical Indonesian snack that is widely favored by the entire community. In the process of making chips it takes the oil drying stage. The purpose of drying oil is to remove the oil content in the chips so that the chips are not rancid. The conventional method commonly used to remove the oil content is by placing the chips on paper. The paper functions to absorb the oil on the chips. In this paper an electric motor-based chips drying machine will be delivered. This machine is built on an induction motor as a driver, an inverter as a speed regulator, and an Arduino Uno microcontroller as a sensor controller. The method of making uses experimental design. This machine will stop automatically when the chips are dry. Three types of chips have been successfully dried with this machine.
\end{abstract}

Keywords: chips dryer, electric motors, Arduino Uno, inverter

\section{PENDAHULUAN}

Kripik merupakan salah satu jenis makanan ringan yang banyak digemari masyarakat Indonesia. Karena itu banyak rumah tangga yang memproduksi kripik. Salah satu tahapan proses produksi kripik adalah penirisan kripik pasca tahap penggorengan. Tujuan penirisan adalah untuk menghilangkan minyak dari kripik. Tahap penirisan merupakan tahapan proses yang sangat penting sebab jika kripik mengandung banyak minyak akan menyebabkan kripik tidak renyah, menimbulkan aroma yang tidak enak (tengik), serta menyebabkan kripik mudah mengalami pembusukan. Dengan kata lain akan menurunkan mutu kripik.

Untuk meniriskan minyak dari kripik, para produsen kripik tradisional biasanya meletakkan dan menggelar kripik yang telah digoreng di atas kertas. Kertas yang dipilih adalah kertas yang mampu menyerap minyak. Kripik dibiarkan beberapa waktu di atas kertas sampai dianggap sudah hilang minyaknya. Kelemahan dari metode ini adalah produsen kripik membutuhkan banyak waktu untuk meniriskan, banyak kertas, dan lahan yang luas. Hal ini menyebabkan jumlah produksi kripik dalam satu kali produksi akan rendah. Oleh sebab itu perlu dirancang alat penirisan yang lebih cepat, tanpa kertas, dan mampu meningkatkan jumlah produksi kripik setiap hari. Masalahnya bagaimana membuat mesin tersebut. 
Perkembangan teknologi bidang elektro telah menghasilkan berbagai alat dan komponen berbasis listrik. Keberadaan alat dan komponen tersebut telah memungkinkan dibentuknya sistem baru berbasis alat dan komponen listrik. Telah banyak mesin peniris kripik dibuat [1,2]. Namun mesin tersebut pada umumnya hanya cocok untuk satu jenis kripik, sehingga membutuhkan mesin berbeda untuk bahan kripik berbeda.

Untuk mengatasi keterbatasan mesin yang ada, tim Jurusan Teknik Elektro Universitas Katolik Widya Mandala Surabaya telah merancang bangun sebuah mesin peniris kripik [3]. Mesin tersebut dipresentasikan dalam makalah ini. Mesin yang dirancang-bangun ini memanfaatkan motor induksi sebagai penggerak, inverter sebagai pengatur kecpatan motor, mikrokontroller arduino uno sebagai pengendali sistem, sensor DHT-22 sebagai pendeteksi suhu dan kelembaban ruang yang datanya dikirimkan ke Arduino Uno. Metode yang digunakan dalam membuat mesin ini adalah metode desain eksperimental. Tujuan dari alat ini adalah agar proses penirisan lebih cepat, jumlah produksi meningkat, tidak menggunakan kertas, tempat penirisan yang tidak luas, dan dapat digunakan untuk meniriskan lebih dari satu jenis kripik. Dengan demikian kendala penirisan model konvensional dapat diatasi.

\section{TINJAUAN PUSTAKA}

Mesin peniris kripik dibutuhkan bagi pengrajin kripik karena sangat membantu untuk menghilangkan minyak yang masih tersisa setelah penggorengan. Ada banyak jenis mesin peniris kripik, namun tiap mesin berbeda kinerja dan spesifikasinya. Mesin peniris kripik yang diberikan PTP Nusantara VII yang diberi nama mesin spinner AGROWINDO mempunyai kapasitas 5 kg dengan kecepatan putaran 900-1200 rpm persentase minyak yang tertiriskan pada putaran $500 \mathrm{rpm}$ dengan lama waktu 80 detik paling tinggi diperoleh pada jenis keripik ubi jalar yaitu 19,5\% [1]. Mesin peniris kripik di laboratorium Pilot Plant FTIP UNPAD memiliki kecepatan putaran motor $650 \mathrm{rpm}$ dengan kapasitas aktual $3,6 \mathrm{~kg} / \mathrm{jam}$ pada daya 120 watt, energi spesifik penirisan $120 \mathrm{~kJ} / \mathrm{kg}$, rendemen penirisan 97,376 \%, efisiensi mesin 65,60\%, indeks performansi mesin 0,95, dan tingkat kebisingan 86,86 dBA [2].

Motor listrik jenis induksi merupakan salah satu jenis motor listrik yang paling banyak digunakan dalam kehidupan manusia. Di dunia industri, motor induksi tiga fasa berjenis rotor sangkar tupai banyak digunakan sebagai penggerak peralatan seperti conveyor, pompa besar, dan peralatan peralatan lainnya. Belakangan ini, motor induksi tiga fasa juga banyak digunakan pada aplikasi kendaaraan elektrik, baik untuk mobil listrik, maupun untuk propulsi pada kapal. Penggunaan motor listrik induksi sebagai pengganti motor bakar tidak hanya menghemat penggunaan bahan bakar minyak yang semakin sedikit cadangannya, namun juga membantu mengendalikan emisi gas buang di alam. Motor induksi tiga fasa jenis rotor sangkar sangat disukai karena memiliki kelebihan berupa ukuran yang relatif kecil, konstruksi sederhana namun kokoh, harga relatif murah, perawatan yang mudah, dan memiliki keandalan tinggi [4]. Keberadaan motor listrik ini dapat digunakan untuk memutar wadah kripik.

Mikrokontroler arduino uno merupakan salah satu komponen elektronika yang banyak digunakan untuk berbagai aplikasi pengendalian [5-7]. Arduino dapat mengolah output dari berbagai sensor untuk pengendalian kondisi yang dibutuhan antara lain menghidup-matikan motor listrik secara otomatis.

Salah satu pengatur kecepatan motor listrik induksi adalah inverter. Hartono, B. P., \& Nurcahyo, E. [8] melakukan penelitian tentang pengendalian kecepatan motor induksi tiga fasa dengan inverter pada mesin extruder. Hasilnya menunjukkan bahwa pada pengendalian kecepatan motor induksi tersebut, energi yang dibutuhkan lebih kecil, penghematan energinya 65,61 kWh dalam pengoperasian 6jam/hari karena kebutuhan kecepatanya hanya 500-600 rpm. 
Kelembaban dan suhu kripik sebelum dan sesudah ditiriskan sangat diperlukan. Oleh sebab itu dibutuhkan sensor suhu dan sensor kelembaban sebagai pemberi masukan kepada mikrokontroller. Sensor DHT 22 adalah sensor yang dapat berfungsi sebagai sensor suhu dan kelembaban. Sensor ini dapat menjadi sumber masukan bagi Arduino. Sensor DHT 22 telah banyak diaplikasikan dalam berbagai penelitian [9-11].

\section{METODE PENELITIAN}

Untuk mewujudkan mesin peniris kripik ini telah diterapkan metode desain eksperimen. Langkah-langkah yang dilakukan meliputi : desain diagram blok sistem keseluruhan, desain cara kerja mesin, desain penentuan bahan, konstruksi bagian mekanik mesin, konstruksi sistem penggerak mesin berbasis motor listrik, konstruksi desain konstruksi mesin sistem pengendali mesin berbasis mikrokontroler arduino uno.

Untuk mengetahui kinerja mesin dilakukan pengukuran besarnya energi listrik dikonsumsi oleh mesin, kecepatan maksimum peniris, dan hasil penirisan untuk berbagai jenis kripik.

\section{Desain diagram blok sistem}

Secara garis besar sistem peniris keripik terbagi menjadi dua bagian yaitu : (1) bagian mekanik, (2) bagian elektronika. Diagram blok sistem secara keseluruhan disajikan lihat pada Gambar 1. Bagian mekanik

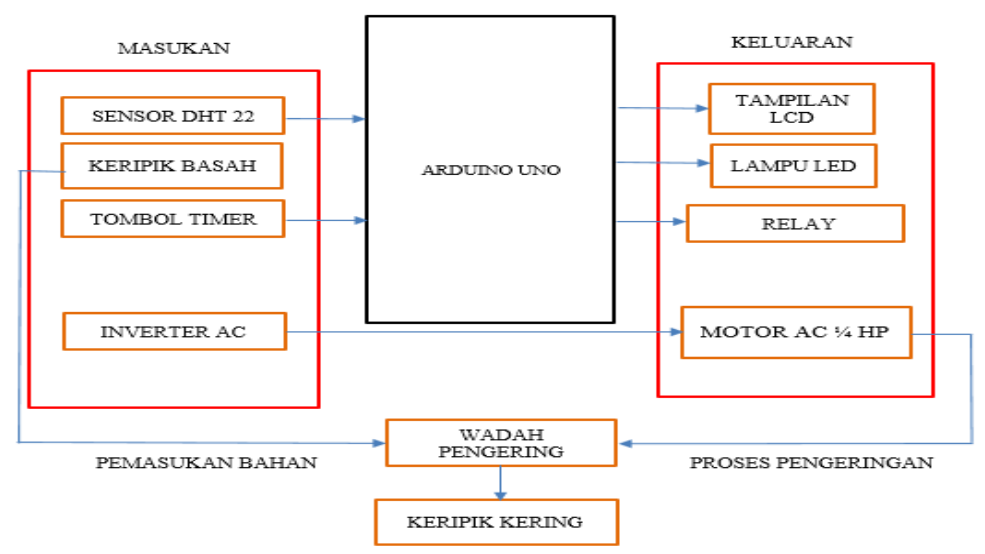

Gambar 1. Gambar diagram blok sistem peniris kripik.

\section{Cara kerja mesin peniris yang dirancang}

Mesin peniris ini dirancang mampu bekerja pada berbagai kecepatan sesuai dengan jenis kripik yang akan ditiriskan. Kecepatan mesin akan berpengaruh pada keutuhan kripik. Adapun cara kerja mesin dibuat sebagai berikut:

1. Mula-mula catu daya ke mesin dihidupkan.

2. Mikrokontroler memerintahkan sensor DHT22 membaca suhu dan kelembaban kripik yang ada dalam tabung penirisan.

3. Mikrokontroller menampilkan hasil pembacaan sensor pada LCD. Data ini mencerminkan kelembaban dan suhu kripik. Nilai kelembaban akan menentukan durasi penirisan dan kecepatan penirisan.

4. Tekan tombol timer untuk menentukan durasi mesin hidup

5. Putar knob pada inverter sesuai dengan kecepatan motor yang dibutuhkan untuk pengeringan. 
6. Tekan tombol run pada inverter sehingga motor listrik akan berputar selama durasi yang telah ditetapkan melalui timer.

7. Jika motor sudah berhenti sesuai durasi yang diberikan berbarti penirisan selesai.

\section{Perancangan Bagian Elektronika}

Bagian elektronik didesain terdiri dari miktokontoler, sensor DHT22, LCD sebagai displai hasil pengukuran, lampu led sebagai indikator kondisi nyala, mati mesin, inverter untuk mengatr kecepatan motor listrik, relay untuk mematikan motor. Pada media peniris akan dipasang satu buah sensor suhu kelembaban (DHT22) di bagian atas dekat tutup tabung. Hal ini bertujuan untuk mengetahui suhu dan kelembaban pada media peniiris. Kemudian diambil nilai rata-rata suhu dan kelembaban, sehingga pengeringan dapat efektif sesuai dengan perbedaan antara kelembaban karena nantinya alat akan dioperasikan saat kondisi keripik panas karena apabila kondisi keripik panas maka minyak lebih cepat terpisah dari kripik karena sifat minyak yang panas lebih cair daripada minyak yang sudah dingin.

Mikrokontroler Arduino Uno digunakan untuk mengatur timer yang nantinya akan mematikan motor AC sesuai waktu yang ditentukan, fungsi lain dari mikrokontroler juga untuk mengatur sensor DHT 22 yang berfungsi untuk melihat suhu dan kelembaban didalam tabung, sehingga nantinya diharapkan suhu di dalam tabung berkisar antara $30^{\circ} \mathrm{C}-70^{\circ} \mathrm{C}$.

Inverter berfungsi sebagai pengatur kecepatan motor dengan cara mengatur frekuensi sesuai kebutuhan, bergantung pada tingkat kerapuhan gorengan yang akan dikeringkan. Inverter yang digunakan merupakan inverter dengan input 1 fase dengan output 3 fase, sehingga motor yang digunakan merupakan motor 3 fase berdaya $1 / 4 \mathrm{HP}$.

Rangkaian driver digunakan agar dapat mematikan motor listrik secara otomatis saat penirisan sudah selesai. Motor yang digunakan merupakan motor 3 fasa dengan catudaya 380 VAC yang berasal dari output inverter. Dengan demikian kontak rellay akan berpindah dari yang semula berada pada kondisi NC (Normaly Close) menjadi berada pada kondisi NO (Normaly Open) untuk mematikan mesin secara otomatis.

Pada Gambar 2 disajikan bagian elektornika sistem yang terdiri dari box panel berisi sistem elektronika yang memiliki dimensi sebesar $37.5 \mathrm{~cm}$ x $30 \mathrm{~cm}$ x $20 \mathrm{~cm}$ (Gambar (2a)) dan layout komponen-komponen seperti pada Gambar (2b).

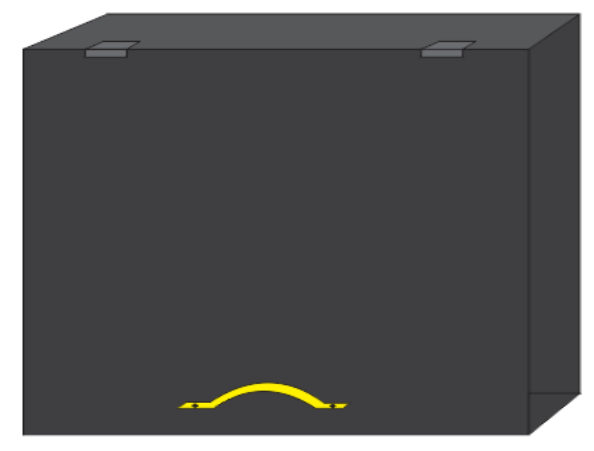

(a)

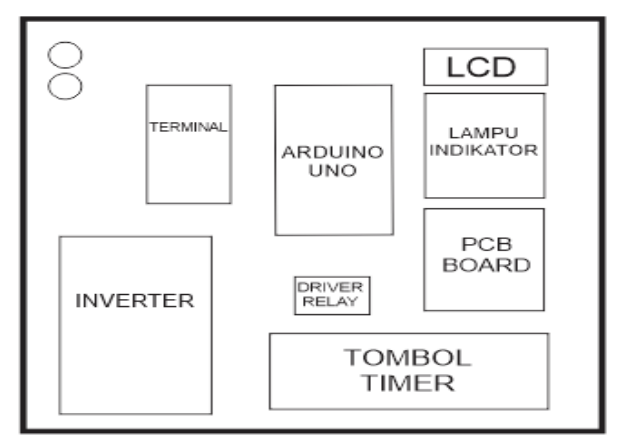

(b)

Gambar 2. Desain Box Panel

(2a). Gambar tampilan luar boc panel

(2b). Gambar layout sistem pengendali yang ada di dalam box panel

\section{Perancangan Bagian Mekanik}


Bagian mekanik dirancang terdiri dari Tutup Tabung, Tabung Luar, Kran Keluaran Minyak, Bearing, Pulley Besar, V-belt, Motor listrik 3 fasa 1/4 PK, Tutup Kerangka, Pulley Kecil, Kerangka, Kotak Panel Pengendali, Poros mesin. Tabung Peniris.Dimensi seluruh bagian mekanik adalah $80 \mathrm{~cm}$ x $50 \mathrm{~cm}$ x $110 \mathrm{~cm}$.

Tabung peniris dibuat berlubang pada bagian dinding sebagai tempat keluarnya minyak dari kripik, dan pada bagian dalam sebelah atas diletakkan sensor DHT 22.

Poros terbuat dari stainless steel agar tidak mudah berkarat yang memiliki panjang sebesar 46 $\mathrm{cm}$ sedangkan untuk ukuran pulley menggunakan 2 ukuran masing-masing berdiameter $18 \mathrm{~cm}$ dan $6 \mathrm{~cm}$. Dimensi tabung luar berdiameter $36 \mathrm{~cm}$ dan memiliki tinggi $40 \mathrm{~cm}$ dilengkapi tutup tabung. Tabung peniris bagian dalam berdiameter $30 \mathrm{~cm}$. Tutup tabung, tabung luar, dan tabung peniris dibuat dari bahan stainless steel agar kripik yang ditiriskan terbebas dari karat. Kerangka mesin terbuat dari besi, dan penutup bagian samping mesin dibuat dari triplex.

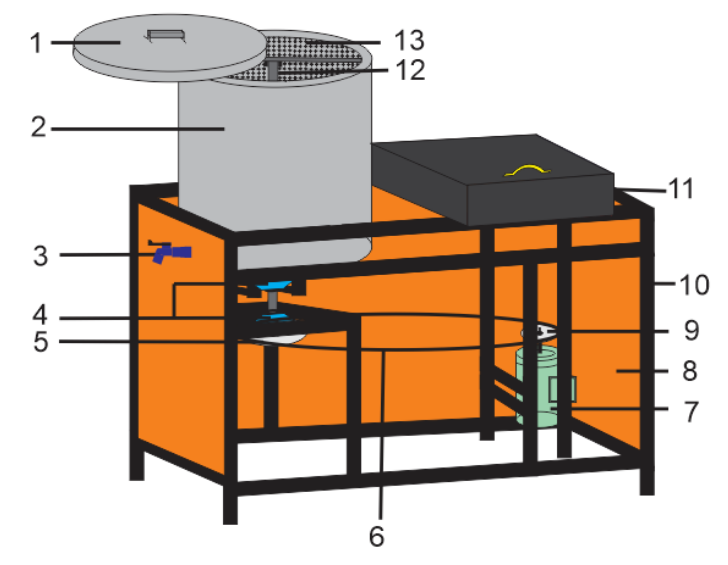

Gambar 3. Gambar konstruksi mesin peniris yang akan diwujudkan.

Keterangan: (1) Tutup Tabung, (2) Tabung Luar, (3) Kran Keluaran Minyak, (4) Bearing, (5) Pulley Besar, (6) V-belt, (7) Motor listrik 3 fasa 1/4 PK, (8) Tutup Kerangka, (9) Pulley Kecil, (10) Kerangka, (11) Kotak Panel Pengendali, (12) Poros mesin (13) Tabung Peniris

\section{HASIL DAN PEMBAHASAN}

Gambar 4 menunjukkan realisasi mesin peniris kripik yang dibangun, sementara itu Gambar 5 menunjukkan bagian elektronika yang ada di dalam box panel.

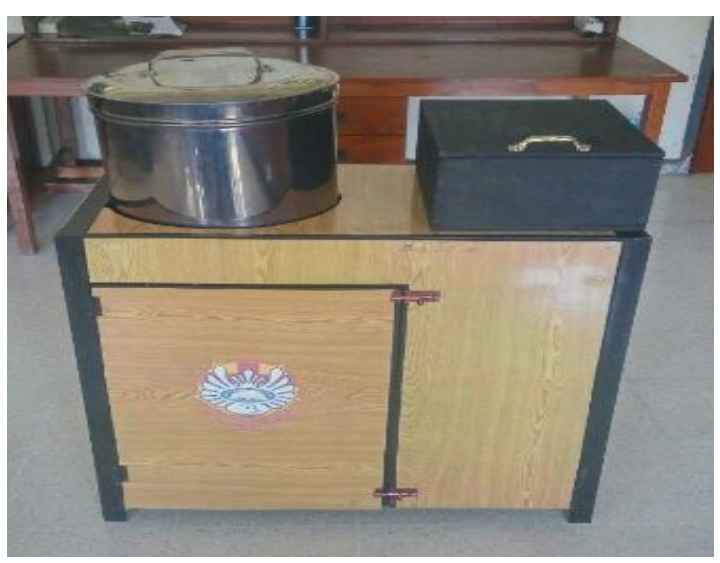

Gambar 4. Gambar realisasi mesin peniris

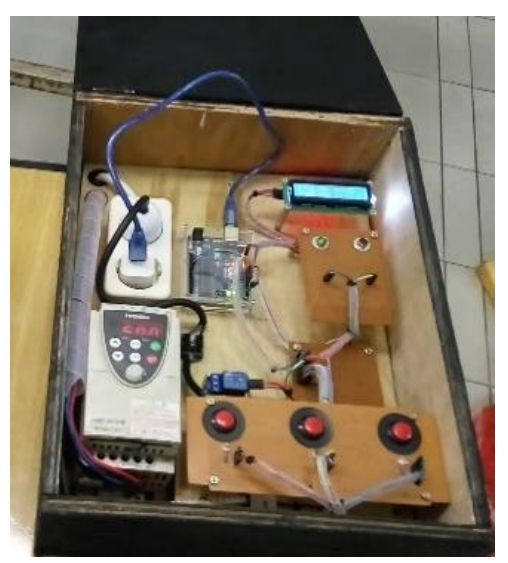

Gambar 5. Gambar bagian elektronika yang ada di dalam box panel 
Mesin ini dilengkapi dengan tiga tombol durasi waktu penirisan masing-masing untuk 5 menit, 10 menit, dan 15 menit.

\section{Pengujian mesin peniris yang direalisasikan}

Untuk mengetahui kinerja alat maka dilakukan pengukuran dan pengujian alat yang dibuat. Adapun parameter yang diukur meliputi: Daya listrik yang dikonsumsi oleh alat menggunakan wattmeter, kecepatan putar tabung menggunakan tachometer dengan tabung peniris dalam keadaan kosong. Pengujian kinerja peniris dilakukan dengan mengukur masa kripik menggunakan timbangan digital sebelum dan sesudah ditiriskan untuk durasi waktu tertentu.

Pengukuran konsumsi daya pada sistem bertujuan untuk mengetahui besarnya daya yang dibutuhkan alat untuk bekerja. Besarnya konsumsi daya yang dibutuhkan pada saat sistem berada pada kondisi standby dan saat mesin berbeban (verter, mikrokontoler, motor) menyala. Kondisi standby merupakan kondisi saat inverter tidak mengaktifkan motor namun tetap mengaktifkan, mikrokontroler, LCD, driver relay dan sensor.

Pengukuran dilakukan dengan menggunakan alat ukur Wattmeter (electronic energy meter) dengan cara menghubungkan alat ukur tersebut pada sumber jala - jala listrik 220VAC dan alat atau mesin peniris.beban yang hendak diukur. Gambar 6 menunjukan skema pengukuran konsumsi daya yang digunakan. Hasil pengukuran konsumsi daya saat tanpa kripik ditunjukkan pada Tabel 1.

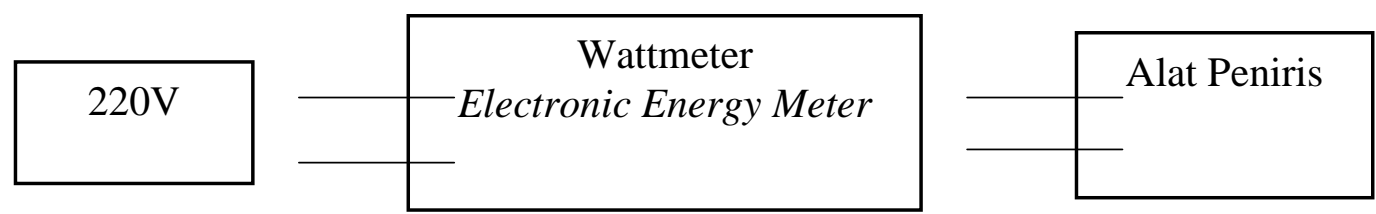

Gambar 6. Gambar skema Pengukuran Konsumsi Daya mesin peniiris.

Tabel 1. Hasil Pengukuran Konsumsi Daya

\begin{tabular}{|c|c|}
\hline Kondisi Sistem & Besar Daya \\
\hline Standby & 1.3 watt \\
\hline Motor listrik hidup tanpa kripik & 120.4 watt \\
\hline
\end{tabular}

Dari Tabel 1 terlihat bahwa konsumsi daya listrik oleh alat saat tanpa beban relatif kecil sebesar 120,4 watt. Namun jumlah daya ini bervariasi saat mesin diberi beban kripik.

\section{Pengukuran Kecepatan Putar Tabung}

Untuk mengetahui besarnya kecepatan putar maksimum tabung, dilakukan pengukuran dengan menggunakan tachometer infrared dengan cara menembakan pancaran sinar laser ke poros tabung. Tabel 2 menunjukkan kecepatan putar maksimum tabung saat frekwensi $50 \mathrm{~Hz}$. Frekuensi diatur dengan menggunakan inverter.

Tabel 2. Hasil Pengukuran Kecepatan Putar Tabung saat tabung peniris tanpa beban

\begin{tabular}{|c|c|}
\hline Frekuensi & $\begin{array}{c}\text { Kecepatan Putar } \\
\text { (RPM) }\end{array}$ \\
\hline $10 \mathrm{~Hz}$ & 101 \\
\hline $20 \mathrm{~Hz}$ & 213 \\
\hline $30 \mathrm{~Hz}$ & 389 \\
\hline $40 \mathrm{~Hz}$ & 592 \\
\hline
\end{tabular}




\begin{tabular}{|l|l|}
\hline $50 \mathrm{~Hz}$ & 733 \\
\hline
\end{tabular}

\section{Pengujian kinerja mesin peniris}

Untuk mengetahui kemampuan mesin peniris tersebut maka dilakukan penimbangan massa kripik goreng sebelum dan sesudah ditiriskan. Pengukuran dilakukan terhadap 3 jenis keripik yaitu keripik rambak, keripik pisang dan keripik emping.. Prosedur pengukuran dilakukan dengan memutar keripik di dalam tabung peniris masing-masing selama 5 menit, 10 menit dan 15 menit. Tiap pemutaran dicatat massa awal keripik, dan massa setelah diputar. Kuantitas minyak pada kripik diperoleh dengan menghitung selisih massa awal dan massa setelah pemutaran / penirisan. Percobaan dilakukan sebanyak 4 kali untuk tiap keripik. Frekuensi inverter yang digunakan ada 2 jenis yaitu frekuensi $50 \mathrm{~Hz}$ untuk keripik rambak dan keripik pisang, serta $40 \mathrm{~Hz}$ untuk keripik emping. Frekuensi untuk keripik emping dibuat lebih rendah agar kecepatan putarnya lebih rendah mengingat keripik emping tersebut yang mudah pecah. Gambar 7, 8 dan 9 masing-masing menunjukkan gambar kripik rambak, kripik pisang, dan kripik emiping yang akan diuji.

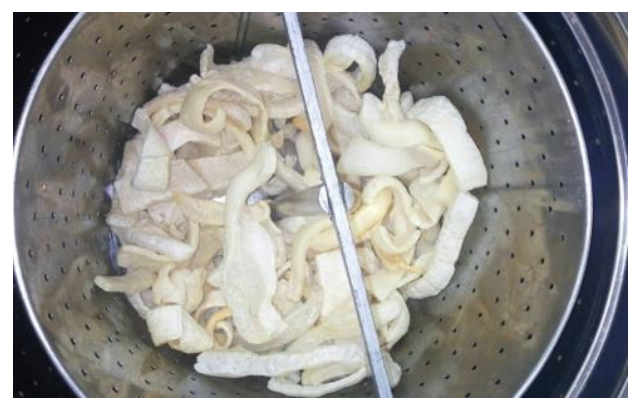

Gambar 7. Gambar kripik rambak yang diuji

Hasil pengukuran ditunjukan pada Tabel 3, 4, dan 5, masing-masing untuk kripik rambak, kripik pisang dan kripik emping.

Tabel 3. Hasil Penirisan Minyak pada Keripik Rambak

\begin{tabular}{|c|c|c|c|c|c|c|}
\hline Percobaan & $\begin{array}{c}\text { Massa Awal } \\
\text { Keripik } \\
\text { (gram) }\end{array}$ & $\begin{array}{c}\text { Putaran } \\
5 \text { menit } \\
(\text { gram) }\end{array}$ & $\begin{array}{c}\text { Putaran } \\
10 \text { menit } \\
\text { (gram) }\end{array}$ & $\begin{array}{c}\text { Putaran 15 } \\
\text { menit } \\
\text { (gram) }\end{array}$ & $\begin{array}{c}\text { Kuantitas } \\
\text { Minyak } \\
\text { (gram) }\end{array}$ & $\begin{array}{c}\text { Kuantitas } \\
\text { Minyak } \\
(\%)\end{array}$ \\
\hline 1 & 332 & 320 & 319 & 319 & 13 & 3.91 \\
\hline 2 & 361 & 349 & 347 & 346 & 15 & 4.15 \\
\hline 3 & 387 & 378 & 376 & 376 & 11 & 2.84 \\
\hline 4 & 359 & 349 & 346 & 346 & 13 & 3.62 \\
\hline Rata-rata & 359.75 & 349 & 347 & 346.75 & 13 & 3.61 \\
\hline
\end{tabular}

Dari Tabel 3 di atas nampak bahwa kuantitas minyak yang melekat pada keripik didapatkan bahwa rata-rata minyak yang berhasil dibuang dari keripik rambak sebanyak 13 gram, dan waktu 10 menit. Jika dibandingkan dengan penirisan konvensional maka penirisan dengan alat ini jauh lebih cepat untuk menghilangkan minyak dari kripik, dimana jika menggunakan metode konvensional penirisan kripik rambak membutuhkan waktu lebih dari dua jam.

Tabel 4. Hasil Penirisan Minyak Pada Keripik Pisang

\begin{tabular}{|c|c|c|c|c|c|c|}
\hline Percobaan & $\begin{array}{c}\text { Massa Awal } \\
\text { Keripik } \\
(\text { gram })\end{array}$ & $\begin{array}{c}\text { Putaran } \\
5 \text { menit } \\
(\text { gram })\end{array}$ & $\begin{array}{c}\text { Putaran } \\
10 \text { menit } \\
\text { (gram) }\end{array}$ & $\begin{array}{c}\text { Putaran } \\
15 \text { menit } \\
(\text { gram })\end{array}$ & $\begin{array}{c}\text { Kandungan } \\
\text { Minyak } \\
(\text { gram })\end{array}$ & $\begin{array}{c}\text { Kandungan } \\
\text { Minyak } \\
(\%)\end{array}$ \\
\hline
\end{tabular}




\begin{tabular}{|c|c|c|c|c|c|c|}
\hline 1 & 500 & 490 & 488 & 488 & 12 & 2.4 \\
\hline 2 & 497 & 486 & 483 & 482 & 15 & 3.01 \\
\hline 3 & 487 & 477 & 476 & 476 & 11 & 2.25 \\
\hline 4 & 513 & 504 & 502 & 501 & 12 & 2.33 \\
\hline Rata-rata & 499.25 & 489.25 & 487.25 & 486.75 & 12.5 & 2.50 \\
\hline
\end{tabular}

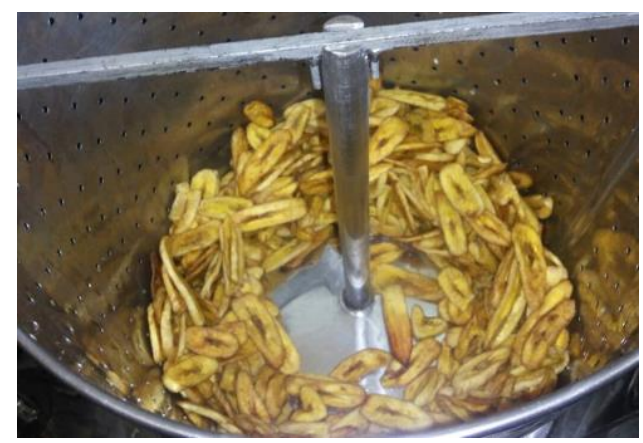

Gambar 8. Gambar kripik pisang yang diuji

Dari Tabel 4 nampak bahwa minyak yang melekat pada keripik pisang berhasil dibuang sebanyak 12.5 gram, dalam waktu pengoperasian selama 10 menit. Hal ini juga menunjukkan bahwa penirisan kripik pisang dengan mesin peniris jauh lebih cepat daripada penirisan dengan konvensional menggunakan kertas.

Tabel 5 menyajikan hasil penirisan minyak pada keripik emping. Dari Tabel 5 nampak bahwa minyak yang melekat pada keripik emping berhasil dibuang sebanyak 16,25 gram, dalam waktu pengoperasian selama 10 menit. Hal ini juga menunjukkan bahwa penirisan emping dengan menggunakan mesin peniris jauh lebih cepat daripada penirisan dengan menggunakan kertas.

Tabel 5. Hasil Penirisan Minyak Pada Keripik Emping

\begin{tabular}{|c|c|c|c|c|c|c|}
\hline Percobaan & $\begin{array}{c}\text { Massa Awal } \\
\text { Keripik } \\
\text { (gram) }\end{array}$ & $\begin{array}{c}5 \\
\text { Menit } \\
\text { (gram) }\end{array}$ & $\begin{array}{c}10 \\
\text { menit } \\
\text { (gram) }\end{array}$ & $\begin{array}{c}15 \\
\text { menit } \\
(\text { gram) }\end{array}$ & $\begin{array}{c}\text { Kandungan } \\
\text { Minyak } \\
\text { (gram) }\end{array}$ & $\begin{array}{c}\text { Kandungan } \\
\text { Minyak (\%) }\end{array}$ \\
\hline 1 & 375 & 360 & 358 & 358 & 17 & 4.53 \\
\hline 2 & 381 & 366 & 366 & 365 & 16 & 4.19 \\
\hline 3 & 387 & 374 & 372 & 371 & 16 & 4.13 \\
\hline 4 & 365 & 351 & 349 & 349 & 16 & 4.38 \\
\hline Rata-rata & 377 & 362.75 & 361.25 & 360.75 & 16.25 & 4.31 \\
\hline
\end{tabular}

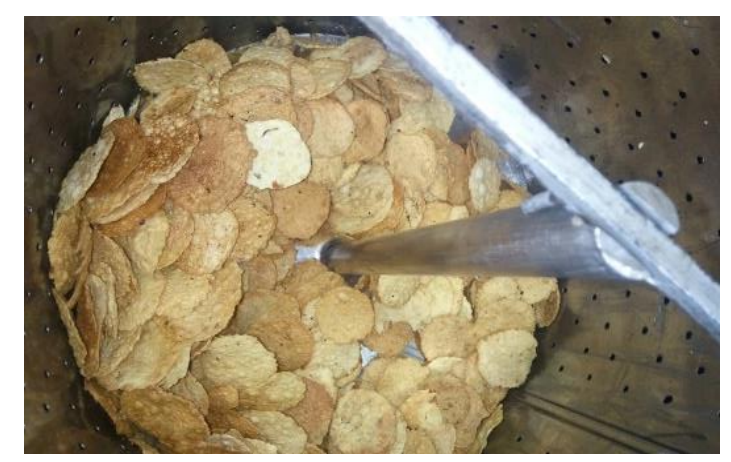

Gambar 9. Gambar kripik emping yang diuji 


\section{KESIMPULAN}

Dalam makalah ini telah diuraikan rancang bangun mesin peniris kripik berbasis motor listrik dan mikrokontroller. Mesin tersebut membutuhkan daya listrik 120 watt dalam keadaan beban nol. Kecepatannya dapat diatur menggunakan inverter. Mesin memiliki tiga pilihan durasi pengeringan yaitu 5 menit, 10 menit dan 15 menit. Penelitian lebih lanjut tentang meisn ini perlu dilakukan untuk mendapatkan spesifikasi serta untuk mendapatkan mesin dengan kinerja yang lebih cepat dan lebih handal.

\section{DAFTAR PUSTAKA}

[1]. Hamimi, H., Tamrin, T. and Setyani, S., 2012. Uji Kinerja Mesin Peniris Minyak Goreng Pada Pengolahan Keripik. Jurnal Teknologi \& Industri Hasil Pertanian, 16(1), pp.91-10.

[2]. Sugandi, W.K., Kramadibrata, A.M., Fetriyuna, F. and Prabowo, Y., 2018. Analisis Teknik dan Uji Kinerja Mesin Peniris Minyak (Spinner)(Technical Analysis and Test Performance of Oil Spinner Machine). Jurnal Ilmiah Rekayasa Pertanian dan Biosistem, 6(1), pp.17-26.

[3]. Prasidya, G. 2018. Mesin peniris keripik goreng berbasis motor listrik dan mikrokontroler (Skripsi, Universitas Katolik Widya Mandala Surabaya), diakses 20 Januari 2019).

[4]. Kurniawan, A. and Harumwidiah, A., 2015. Strategi Kendali Kecepatan Motor Induksi Menggunakan PWM Inverter Berbasis Jaringan Saraf Tiruan. Transmisi, 17(2), pp.83-88.

[5]. Syofian, A., 2016. Pengendalian Pintu Pagar Geser Menggunakan Aplikasi Smartphone Android dan Mikrokontroler Arduino Melalui Bluetooth. Jurnal Teknik Elektro-ITP, 5(1).

[6]. Dani, A.W., Adriansyah, A. and Hermawan, D., 2016. Perancangan Aplikasi Voice Command Recognition Berbasis Android dan Arduino Uno. None, 7(1)

[7]. Silvia, A.F., Haritman, E. and Mulyadi, Y., 2014. Rancang Bangun Akses Kontrol Pintu Gerbang Berbasis Arduino Dan Android. Electrans, 13(1), pp.1-1

[8]. Hartono, B.P. and Nurcahyo, E., 2017. Analisis Hemat Energi Pada Inverter Sebagai Pengatur Kecepatan Motor Induksi 3 Fasa. Elektrika: Jurnal Teknik Elektro, 1(1), pp.8-16.

[9]. Kaewmard, N., \& Saiyod, S. (2014). Sensor data collection and irrigation control on vegetable crop using smart phone and wireless sensor networks for smart farm. In 2014 IEEE Conference on Wireless Sensors (ICWiSE) (pp. 106-112).

[10]. Saptadi, A.H., Kurnianto, D. and Suyani, S., 2015. Rancang Bangun Thermohygrometer Digital menggunakan Sistem Mikropengendali Arduino Dan Sensor Dht22. Prosiding SNST Fakultas Teknik, 1(1).

[11]. Bogdan, M., 2016; . How to use the DHT22 sensor for measuring temperature and humidity with the arduino board. ACTA Universitatis Cibiniensis, 68(1), pp.22-25 